\title{
Peripheral Neuroectodermal Tumor (PNET) of the Breast - a 6-Year Follow-Up
}

\author{
Anke Thomas ${ }^{a}$ Jens U. Blohmer ${ }^{b}$ Andreas Turzynskic ${ }^{c}$ Orhan Sezer ${ }^{d}$ Thomas Fischer ${ }^{e}$ \\ Gundula Thiel $^{\mathrm{f}} \quad$ Manfred Dietelg $^{\mathrm{g}} \quad$ Werner Lichtenegger $^{\mathrm{a}} \quad$ Sherko Kümmel $^{\mathrm{h}}$ \\ a Department of Senology, University Medicine Berlin, Charité, \\ ${ }^{b}$ Department of Senology, St. Gertrauden Hospital, \\ ${ }^{c}$ Gemeinschaftspraxis für Pathologie, Lübeck, \\ dDepartment of Medical Oncology and Hematology, University Medicine Berlin, Charité, \\ e Institute of Radiology, University Medicine Berlin, Charité, \\ f Institute for Genetics, \\ g Institute of Pathology, University Medicine Berlin, Charité, Berlin, \\ ${ }^{h}$ Department of Gynecology and Obstetrics, University Essen, Germany
}

\section{Key Words}

Breast cancer - Neuroectodermal tumor .

Ewing's sarcoma

\section{Summary}

Background: Peripheral primitive neuroectodermal tumors (PNET) are usually located in bone or soft tissue in children or young adults but can also appear at a more advanced age. Case Report: A 60-year-old woman was admitted to our hospital presenting with a tumor of the right breast. Imaging studies led to the diagnosis of suspected benign lesion. Cytologic examination showed atypical cells. The biopsy showed a tumor composed of medium-sized tumor cells with round and ovoid vesicular nuclei and ill-defined cellular margins. The growth pattern was mainly solid in cell clusters. Focally sinusoidal, blood-filled spaces were present. Cytogenetic examination of 20 metaphases showed the karyotype $46, X X, t(11 ; 22)(q 24, q 12) / 46, X X$. Mastectomy was performed, and adjuvant chemotherapy and radiotherapy were given. After a follow-up of 72 month, the patient is alive without evidence of disease. Conclusion: The adjuvant therapy (VACA regime) seems to lead, independently from tumor localization and patient age, to longer disease-free survival.

\section{Schlüsselwörter \\ Brustkrebs - Neuroektodermaler Tumor . Ewing-Sarkom}

\section{Zusammenfassung}

Hintergrund: Periphere neuroektodermale Tumoren (PNET) sind normalerweise in Knochen oder Bindegewebe bei Kindern oder Jugendlichen lokalisiert und nur selten im fortgeschrittenen Alter nachweisbar. Fallbericht: Eine 60-jährige Frau stellte sich mit einem rechtsseitigen Mammatumor vor. Die bildgebende Untersuchung resultierte in der Verdachtsdiagnose gutartiger Tumor. Die zytologische Untersuchung zeigte atypische Zellen. Das histologische Bild nach Stanzbiopsie ergab mittelgroße Tumorzellen mit runden und ovalen Vesikeln im Zellkern und unscharf begrenzten Zellrändern. Das Wachstumsmuster war hauptsächlich solide in Form von Zellballen. Es zeigten sich fokale, sinusoidale, blutgefüllte Hohlräume. Die zytogenetische Untersuchung ergab einen Karyotyp $46, X X, t(11 ; 22)(q 24, q 12) / 46, X X$. Eine Mastektomie mit anschließender adjuvanter Chemotherapie und Radiatio wurde durchgeführt. Nach einer Nachbeobachtung von 72 Monaten war die Patientin weiterhin krankheitsfrei. Schlussfolgerung: Die adjuvante Chemotherapie (VACA -Regime) scheint unabhängig von Tumorlokalisation und Patientenalter zu einem längeren krankheitsfreien überleben zu führen

\begin{tabular}{ll}
\hline KARGER & ( ) 2006 S. Karger GmbH, Freiburg \\
Fax +497614520714 & Accessible online at: \\
$\begin{array}{l}\text { E-mail Information@Karger.de } \\
\text { www.karger.com }\end{array}$ & www.karger.com/brc
\end{tabular}

Dr. med. Anke Thomas

Klinik für Gynäkologie, Interdisziplinäres Brustzentrum

Universitätsmedizin Berlin, Campus Charité Mitte

Schumannstraße 20/21, 10117 Berlin, Germany

Tel. +49 30 4505-64022, Fax -64922

E-mail anke.thomas@charite.de 


\section{Introduction}

The Ewing's tumor family comprises a subclass of morphologically primitive bone and soft tissue malignancies and includes peripheral primitive neuroectodermal tumors (PNET) which occur mainly in children, Ewing's sarcoma and neuroblastoma [1]. These tumors represent the second most common group of malignant bone tumors in children and young adults [2]. Immunohistochemistry is used to distinguish Ewing's sarcoma from PNET. Ewing's sarcoma and PNET cells express CD99 ${ }^{\mathrm{MIC}}$ antigen coded by the MIC2 gene within the pseudoautosomal region of the $\mathrm{X}$ and $\mathrm{Y}$ chromosomes [3]. More importantly, the sarcoma group is characterized by a unique gene rearrangement which is represented by the translocation $\mathrm{t}(11 ; 22)(\mathrm{q} 24 ; \mathrm{q} 12)$ or the deletion del 22q12 in most cytogenetically analyzed cases [4].

While PNET has a relatively high incidence in children, it is only rarely diagnosed in patients over the age of 30. PNET occurring in children must be differentiated from other so-called small, round cell tumors, such as rhabdomyosarcoma and neuroblastoma, whereas the differential diagnosis of small round cell tumors in adults has to take into account malignancies such as small cell carcinomas, neurogenic sarcoma and lymphoma. PNET is a very aggressive neoplasm which develops hematogenous metastases. Prior to the era of systemic treatment, over $90 \%$ of PNET patients died within 2-5 years following the initial diagnosis, with $25-50 \%$ of patients presenting with metastases. Improvements in disease-free survival were obtained after it was determined that PNET responded to various chemotherapeutic agents, particularly alkylating agents and anthracyclines. After introduction of treatment with these agents, the Kaplan-Meier estimate of disease-free survival was $56 \%$ at 3 years in a group of 32 patients with PNET in stage M0 at the initial diagnosis [5]. In another report, 5-year overall survival in patients without metastases at presentation was $52 \%$, and 5-year progression-free survival was $34 \%$ [6].

PNET is most often present as a bone or soft tissue mass in the trunk or axial skeleton. Our study group was the first worldwide to publish typical chromosomal aberrations and molecular genetic findings of a PNET arising in the breast as a primary tumor in 1999 (Medline 1976 to December 2006) [7]. Here, we report the clinical symptoms, imaging findings, cytological and histological results in more detail and present the follow-up of this unusual case.

\section{Case Report}

\section{Clinical History}

The history of the 60-year-old woman and her family was uneventful. There were, in particular, neither benign nor malignant breast diseases. The menarche occurred at 14.5 years, the menopause at 53 years of age. 2 children were born following spontaneous and uneventful pregnancies. Four months before presentation in the clinic, the patient had fallen at

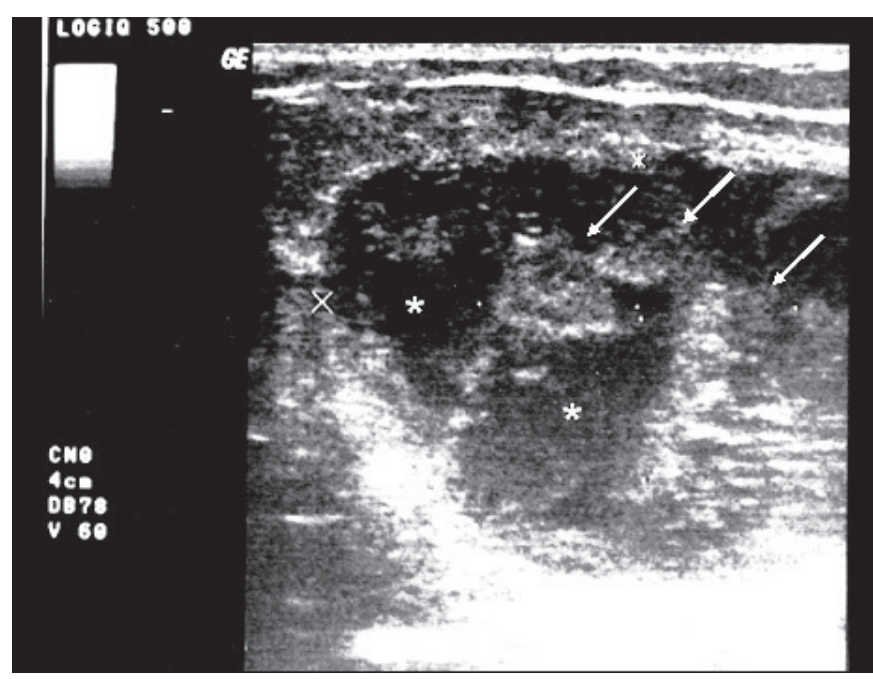

Fig. 1. Mammasonography: echo-poor focal finding with echo-rich septa and irregular internal structures, a smooth tumor wall, horizontal tumor axis, dorsal sound amplification, a lack of lateral border shadows; displacement of the surrounding architecture.

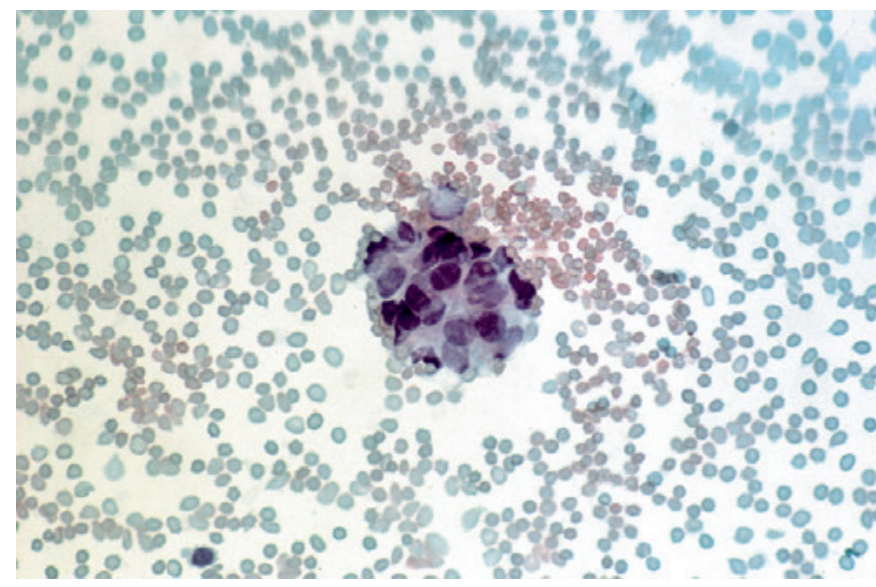

Fig. 2. Cytology: staining according to Papanicolaou $(\times 400)$ showed considerable number of erythrocytes, in part disintegrating. Individual cells show a shift in the nucleus-cytoplasm ratio towards the nucleus, with hyperchromatic nuclei with coarse chromatin.

home after which a suspected hematoma had developed in the right breast. The patient palpated an indolent tumor in the right breast, below the mamilla, which increased in size during the 4 months. 3 months after the accident, the patient consulted a gynecologist because of the tumor. After unsuccessful treatment of the hematoma, she was referred to the outpatient clinic.

On the right breast, a centrally located, indolent, not movable but deformable lesion with a smooth surface and a maximum diameter of approximately $5 \mathrm{~cm}$ was palpated. Mammography revealed a $7-\mathrm{cm}$, smooth, slightly lobulated mass in the lateral and caudal breast, close to the chest wall. The mass had a homogeneous, relatively low density with no internal calcifications. The suspected diagnosis was a cyst, as a differential diagnosis, a hematoma was considered. Corresponding to the palpation finding, mammasonography (fig. 1) showed an echo-poor lesion with a maximum diameter of $34 \mathrm{~mm}$, with echo-rich septa and an irregular internal structure, a smooth tumor wall, a horizontal tumor axis, no dorsal sound atten- 


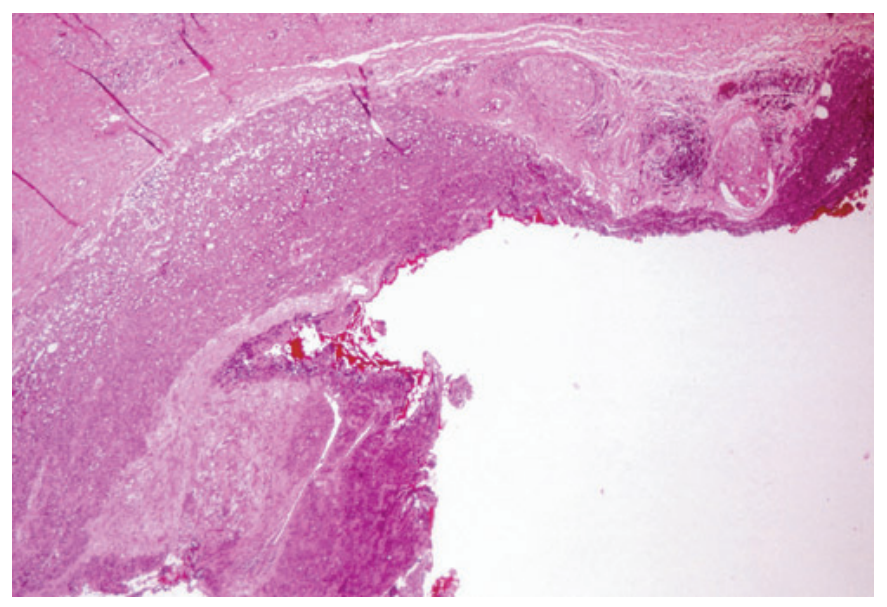

Fig. 3. Histology: HE staining $(\times 40)$. Histology of the primitive neuroectodermal tumor of the breast: at low-power magnification, the hematoma cavity lined by narrow tumor sheets is visible. The adjacent breast tissue and even 2 intramammary nerves in intimate proximity to the tumor are uninvolved.

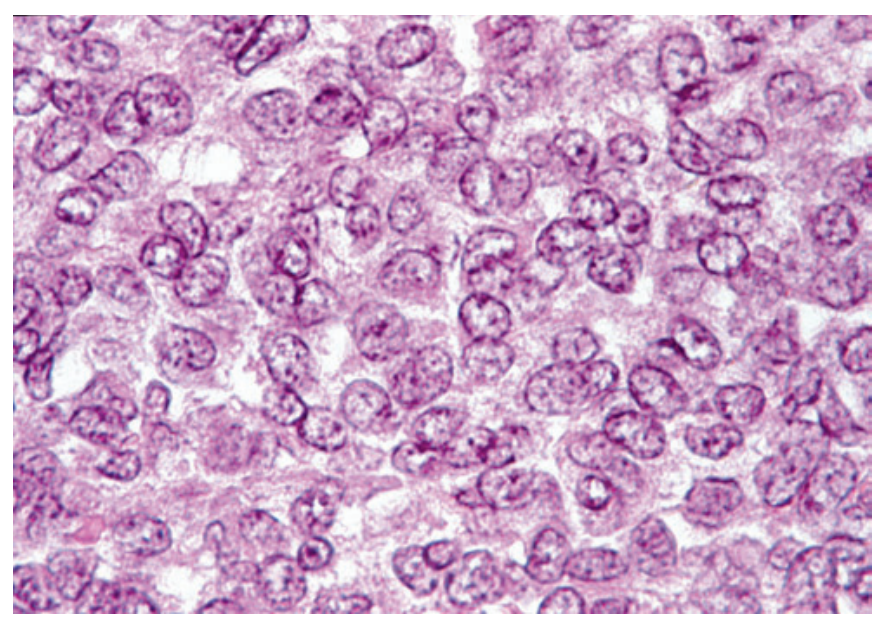

Fig. 4. Histology: HE staining. The high-power magnification shows densely packed, relatively uniform tumor cells with vesicular nuclei. uation, a lack of lateral border shadows and displacement of the surrounding mammary architecture. In both axillae, there were sonographically inconspicuous lymph nodes with intact medullar-cortex structure, with the right lymph nodes having a maximum diameter of $27 \mathrm{~mm}$. Colorcoded duplex sonography of the breast tumor showed an ample flow of blood with a maximum systolic velocity of $6 \mathrm{~cm} / \mathrm{s}$ in the border areas extending into the lesion. Differential diagnosis included abscess or centrally necrotic tumor located in the center of the right breast. A computed tomography (CT) scan revealed a large soft tissue mass located laterally in the right breast with a thick, irregular wall and low-density center, indicating necrosis. No metastases were determined at CT examination of the thorax and abdomen or at skeletal scintigraphy.

\section{Materials and Methods}

For cytological examination, an ultrasound-guided fine needle aspirate (fig. 2) was carried out. $5 \mathrm{ml}$ of blood-tinged fluid was stained according to Papanicolau and investigated using light microscopy with a magnification of $100-400 x$.

Histology and immunohistochemistry (fig. 3-4) were performed using a core-cut biopsy and a subsequent open biopsy, both initially processed for frozen sections. The conventional hematoxylin-eosin (HE) staining and a broad panel of immunohistochemical markers were applied. In 10 high power fields the mitoses were counted.

Cytogenetic analysis was performed on cells from a primary culture. Slides were prepared by conventional technique and G-banding using the trypsin-Giemsa method. Details are described in our publication cited above [7].

\section{Results}

Cytology showed a large number of erythrocytes, in part disintegrating. Individual cells with a shift in the nucleus-cytoplasm ratio in favor of the nucleus presented with hyperchromatic nuclei containing coarse chromatin (fig. 2). Histology revealed that on the cut surface of the ablated breast, the tumor was located deeply in the retromamillary space, with the outer quadrants forming a $55 \times 20 \mathrm{~mm}$ blood-filled cavity with solid brownish-gray tumor infiltrates in the wall. The solid tumor portion was predominantly located in the inferior wall of the cavity and had relatively well-defined margins against the adjacent tissue, while the upper walls of the cavity were only partially covered by tumor sheets. Material for cell culture and cytogenetic examination was obtained. Histologically, the tumor was composed of medium-sized tumor cells with round and ovoid vesicular nuclei and ill-defined cellular margins. The growth pattern was mainly solid in cell clusters. Focally, sinusoidal blood-filled spaces were present. No rosettes were found. The cytoplasm of some of the tumor cells contained periodic acid-Schiff (PAS)-positive granules. In 10 high power fields 14 mitoses were counted. The invasion front showed a closed pattern, focally resembling Indian file formations extending tangentially from the tumor margin. Pre-existing ducts or lobules were not involved.

Immunohistochemistry led to the diagnosis of a sarcoma of the Ewing's sarcoma group based primarily on the conventional histology and immunopositivity for CD99 ${ }^{\mathrm{MIC}}$, vimentin and S100 protein and neuron-specific enolase. The tumor cells stained negative for a panel of other markers (MNF116, EMA, CK8/18/19, CK20, CD31, CD34, chromogranin, synaptophysin, CD56, CD57, neurofilament protein, GFAP, CD45 and myoglobin) to exclude epithelial, endothelial, neuroendocrine, lymphocytic or muscular lineages. The tumor cells stained slightly for sarcomeric actin. The antibody MIB1 stained an inhomogeneously distributed fraction of 10-20\%. The cytogenetic examination of 20 metaphases revealed the karyotype 46,XX,t(11;22)(q24,q12)[13] / 46,XX[7]. The t(11; 22) translocation is characteristic for PNET.

After histologic confirmation of the breast malignancy, a modified ablatio mammae was carried out due to the size of the tumor and its central location. In addition, a partial resection 
of the surface of the musculus pectoralis major was performed because the tumor was located close to the thoracic wall. The axillary lymph nodes were inconspicuous and of normal size. They were not removed because of the exclusively hematogenic metastasis of PNET and the negative imaging findings. The borders of the resection were free of tumor tissue (R0 resection). There were no post-operative complications and the wound healed without infection. Adjuvant chemotherapy was started 10 days after surgery using the VACA protocol: vincristine $1.5 \mathrm{mg} / \mathrm{m}^{2}$, days $1+21$; adriamycin $20 \mathrm{mg} / \mathrm{m}^{2}$, days 1,2 , 3; cyclophosphamide $1,200 \mathrm{mg} / \mathrm{m}^{2}$, days $1+21$; actinomycin D $0,5 \mathrm{mg} / \mathrm{m}^{2}$, days $21,22,23$; cycles repeated every 6 weeks over 8 cycles. After 2 cycles, granulocyte colony-stimulating factor (G-CSF) support was necessary for subsequent treatment. The chemotherapy was followed by adjuvant radiation therapy of the thoracic wall with 50 Gy. 72 months have passed since the patient was operated on without local or systemic recurrence.

\section{Discussion}

Although there have been reports of metastatic PNET involving the breast [8,9], a Medline search (1976-2006) revealed only 1 publication on PNET of the breast as a primary tumor [7]. According to our experience with the current patient, the clinical findings first resembled those of a hematoma, which however increased in size. Both the sonographic and the CT images suggested a necrotic process. Immediate cytological and histological evaluations were performed. The immunohistochemical and cytogenetic investigations resulted in a definitive diagnosis of PNET. Cytogenetic analysis of the tumor material showed a $\mathrm{t}(11 ; 22)(\mathrm{q} 24 ; \mathrm{q} 12)$ translocation, a genetic rearrangement occurring in approximately $85 \%$ of PNET [10]. According to the diagnostic algorithms of Schmidt et al. [11], the tumor was classified as a primitive neuroendocrine tumor of the breast. The comprehensive diagnostic procedure revealed no other organ involvement.

Intensive combination chemotherapy has become standard in the adjuvant treatment of PNET in children. An Intergroup Ewing's Sarcoma Study has shown the superiority of the 4drug VACA regimen over a 3-drug regimen with vincristine, actinomycin D and cyclophosphamide (VAC) in terms of 5year relapse-free survival (60 vs. 24\%) [12, 13]. Although more intensive chemotherapy may be beneficial in children, it must be taken into account that adults tolerate intensive chemotherapy less well than children. In the patient described here, it was only possible to administer repeated cycles of the VACA protocol with G-CSF support. It seems that the use of adjuvant chemotherapy by VACA regime independently from tumor localization and patient's age leads to longer diseasefree survival.

\section{Acknowledgment}

The authors are indebted to Prof. Dr. H. Jürgens, Director of Institute for Pädiatrische Hämatologie/Onkologie der Westfälischen Wilhelms-Universität, Münster, Germany, for discussion of the present case.

\section{References}

1 Roessner A, Jürgens HF: Round cell tumors of bone. Pathol Res Pract 1993;189:1111-1136.

2 Jürgens HF: Ewing's sarcoma and peripheral primitive neuroectodermal tumor. Curr Opin Oncol 1994;6:391-396.

-3 Kovar H, Dworzak M, Strehl S, et al.: Overexpression of the pseudoautosomal gene MIC2 in Ewing's sarcoma and peripheral primitive neuroectodermal tumor. Oncogene 1990;5:1067-1070.

4 Delattre O, Zucman J, Plougastel B, et al: Gene fusion with an ETS DNA-binding domain caused by chromosome translocation in human tumours. Nature 1992; 359:162-165.

5 Jürgens HF, Bier V, Harms D et al: Malignant peripheral neuroectodermal tumors. A retrospective analysis of 42 patients. Cancer 1988;61:349-357.
6 Verrill MW, Judson IR, Harmer CL, et al.: Ewing's sarcoma and primitive neuroectodermal tumor in adults: are they different from Ewing's sarcoma and primitive neuroectodermal tumor in children? J Clin Oncol 1997;15:2611-2621.

7 Sezer O, Jugovic D, Blohmer JU, et al: CD99 positivity and EWS-FL11 gene rearrangement identify a breast tumor in a 60-year-old patient with attributes of the Ewing family of neoplasms. Diagn Molecular Path 1999;8:120-124.

8 Silverman JF, Berns LA, Holbrook CT, et al: Fine needle aspiration cytology of primitive neuroectodermal tumors. A report of these cases. Acta Cytol 1992;36:541-550.

9 Kwak JY, Kim EK, You JK, et al: Metastasis of primitive neuroectodermal tumor to the breast. J Clin Ultrasound 2002;30:374-377.
10 Turc-Carel C, Aurias A, Mugneret F, et al.: Chromosomes in Ewing's sarcoma. I. An evaluation of 85 cases of remarkable consistency of $\mathrm{t}(11 ; 22)$ (q24;q12). Cancer Genet Cytogenet 1988;32: 229-238.

11 Schmidt D, Herrmann C, Jürgens HF, Harms D: Malignant peripheral neuro- ectodermal tumor and its necessary distinction from Ewing's sarcoma. A report from the Kiel Pediatric Tumor Registry. Cancer 1991;68:2251-2259.

12 Nesbit ME Jr, Gehan EA, Burgert EO, et al: Multimodal therapy for the management of primary, nonmetastatic Ewing's sarcoma of bone: a longterm follow-up of the First Intergroup study. J Clin Oncol 1998:1664-1674.

13 Aparicio J, Munarriz B, Pastor M, et al: Long-term follow-up and prognostic factors in Ewing's sarcoma. A multivariate analysis of 116 patients from a single institution. Oncology 1998;55:20-26. 